\title{
Operational definitions of asthma in studies on its aetiology
}

\author{
J. Pekkanen*, J. Sunyer" J.M. Anto" and P. Burney ${ }^{\#}$, on behalf of the European \\ Community Respiratory Health Study (ECRHS)
}

\begin{abstract}
The most popular way to define asthma based on questionnaires is to use definitions taken from cross-sectional international studies on asthma. These definitions may not, however, be optimal for future studies focusing on risk factors of asthma. The current authors, therefore, compared the performance of different operational definitions of asthma.

The European Community Respiratory Health Study I was a cross-sectional study of 21,924 subjects aged between 25-44 yrs in 18 countries. Operational definitions of asthma compared included different combinations of symptoms of asthma and bronchial hyperresponsiveness. A continuous asthma score, ranging from $0-8$, was defined as the sum of positive answers to eight main symptom questions.

There was no threshold in the associations of asthma symptoms with severity or risk factors of asthma, which would have suggested a dichotomous definition of asthma. Using dichotomous definitions requiring the presence of several asthma symptoms strengthened associations with studied risk factors, and also increased the estimated specificity and positive predictive value. Using a continuous asthma score also improved the power of the analyses.

In conclusion, dichotomous definitions of asthma yielding higher odds ratios are achieved by requiring positive responses to several questions on symptoms. However, symptoms of asthma are possibly best analysed as a continuous asthma score.
\end{abstract}

KEYWORDS: Asthma, definition, epidemiology, methods, risk factor

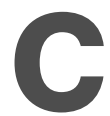
urrently there is disagreement on the exact pathophysiology of asthma and, therefore, it is unclear how asthma should be exactly defined in future studies [ 1 , 2]. In epidemiology, the most common solution has been to adopt questionnaires and dichotomous operational definitions of asthma developed for large cross-sectional prevalence studies, such as the European Community Respiratory Health Study (ECRHS) [3], and the International Study of Asthma and Allergies in Childhood (ISAAC) [4]. However, definitions of asthma used in these studies may not be optimal for future studies focusing on risk factors of asthma.

Choosing a cut-off point for a dichotomous definition of disease is a difficult trade-off between sensitivity and specificity. This has been repeatedly shown for continuous traits, such as bronchial hyperresponsiveness (BHR) [5]. The best cut-off point depends largely on the aims of the study. Dichotomising a continuous variable also leads to a loss in power [6].

For editorial comments see page 3 .
Clinical diseases, e.g. asthma, are usually treated as dichotomies in epidemiological research. However, most, if not all, chronic diseases are not true dichotomies [7]. This was first recognised for physiological traits, such as blood pressure [8], but has been later recognised for several chronic diseases, for instance dementia [9, 10]. Among asthmatics, continuous symptom scores have been used to measure asthma severity and asthma-related quality of life [11]. However, the possibility of combining different symptoms [12] or using a continuous asthma score [13] to define asthma has been less explored.

In the present study, the performance of several dichotomous operational definitions of asthma and a continuous score of asthma symptoms were compared using data from a large international cross-sectional study on asthma in adults, the ECRHS-I [14]. The aim of the present study was to identify possibilities of using existing and future data on symptom questionnaires more efficiently when exploring risk factors of asthma, and to identify the needs for future development of asthma questionnaires.
AFFILIATIONS

*National Public Health Institute,

Kuopio, Finland, and

\#Inst. Municipal D'Investigacio Medica (IMIM), Barcelona, Spain, and

'Dept Public Health Sciences, King's

College, London, UK.

CORRESPONDENCE

J. Pekkanen

Unit of Environmental Epidemiology

National Public Health Institute

P.0. Box 95

70701 Kuopio

Finland

Fax: 35817201265

E-mail: Juha.Pekkanen@ktl.fi

Received:

October 212004

Accepted after revision:

March 292005

SUPPORT STATEMENT

The coordination of the present study and the fellowship of J. Pekkanen at the Institute Municipal D'Investigacio Medica (Barcelona, Spain), were supported by the European Commission. 


\section{METHODS}

The protocol for the ECRHS has been described elsewhere [14, 15]. Briefly, participating centres selected an area defined by pre-existing administrative boundaries, with a population of $\geqslant 150,000$ individuals. An up-to-date sampling frame was used to randomly select $\geqslant 1,500$ males and 1,500 females, aged between 20-44 yrs. In stage I, subjects were sent a questionnaire enquiring about respiratory symptoms. A 20\% random sample of subjects was selected to take part in stage II in which they were invited to answer a more detailed administered questionnaire, and to take part in blood tests, skin tests, assessment of lung function by spirometry and airway challenge with methacholine. The present study included only subjects randomly selected to stage II from 34 centres in 15 countries (Belgium (2), Germany (2), Spain (5), France (4), Ireland (1), Italy (3), Netherlands (3), UK (3), Iceland (1), Norway (1), Sweden (3), Switzerland (1), New Zealand (3), USA (1) , and Australia (1)). For the present analyses, subjects with missing data on any of the questions on asthma symptoms, BHR testing or on atopy were excluded, leaving a total of 11,297 subjects. The study protocol was approved by the Institutional Review Board of the participating centres. Participants gave informed written consent.

The ECRHS questionnaire at stage II was adapted from a preexisting questionnaire [16]. The questions were tested for comprehensibility and translated, with back translation into English. The results from the questionnaire have been reported elsewhere [17], including respiratory symptoms, questions on asthma diagnosis and asthma treatment.

Current smoking was defined as those reporting having smoked during the last month and atopy as a specific immunoglobulin $\mathrm{E}>0.35 \mathrm{kU} \cdot \mathrm{L}^{-1}$ to any of the following allergens: house dust mite (Dermatophagoides pteronyssinius), cat, timothy grass and Cladosporium Herbarum.

\section{Operational definitions of asthma used}

At stage II of the ECRHS questionnaire, there were 12 main questions on asthma symptoms (Appendix 1; numbering taken from the original questionnaire) [14]. Different combinations of these questions were used to devise different operational definitions of asthma.

Wheeze was defined in three different ways: 1) wheeze, positive answer to question $1 ; 2$ ) wheeze and breathlessness, positive answers to questions 1 and 1.1; and 3) wheeze and breathlessness, no cold, positive answers to questions 1, 1.1 and 1.2.

The above variables were combined in addition to positive results from the BHR test (dose of methacoline causing a $20 \%$ fall in forced expiratory volume in one second (PD20 ) $<1 \mathrm{mg}$ ) [18] to create the following variables: 1 ) wheeze and BHR; 2) wheeze and breathlessness and BHR; and 3) wheeze and breathlessness, no cold, and BHR.

BHR was also analysed by itself, using three different definitions of abnormal result from the BHR test: a slope $>25 \%$, a slope $>10 \%$ or PD20 $<1 \mathrm{mg}$ [18].

The questions used in the ECRHS to select subjects with possible asthma [15] were questions 5, 13.5 and 13.6 (attack of shortness of breath, attack of asthma, and use of asthma medication). Using these questions, three ECRHS definition combination variables were defined. 1) Any one of three variables: positive answer to at least one of the above questions. 2) Any two of three variables: positive answer to at least two of the above questions. 3) All three variables: positive answer to all three questions.

\section{Asthma score}

To explore continuous combinations of the asthma questions, a principal component analyses was run with all the 12 main questions on asthma symptoms available (Appendix 1). Three main factors in the principal component analyses had Eigen values of 4.57, 1.69, and 1.12, respectively. All three factors were explored in an attempt to analyse phenotypes of asthma (see results).

However, given the strength of the first factor and the main aim of the present study, the decision was made to use only one factor to build the main asthma score. First, an effort was made to reduce the number of questions used to build the score. This was done to avoid categories of score with very few observations. Question 6 on cough was excluded first, as it had a very low factor loading (0.27). The wheezing questions were highly correlated, so only one question on wheezing was selected, wheeze and breathlessness, since it had slightly higher loading (0.72) than other wheezing questions (0.68 and 0.65 , respectively). Based on the same reasoning, the question on doctor-diagnosed asthma (loading 0.73) was dropped, but question 13 was retained (loading 0.74).

The standardised Cronbach's alpha, which measures the internal consistency of the components of a score, was 0.82 for the previously mentioned eight questions. Deleting any of the other questions on asthma dropped the Cronbach's alpha to $0.78-0.79$; so all three questions were retained. Adding any of the questions that were previously dropped did not increase the Cronbach's alpha higher than 0.83, except for the doctor diagnosis of asthma, which increased it to 0.85 . However, asthma and doctor diagnosis of asthma contain essentially the same information $(92 \%$ of subjects with ever asthma have a diagnoses of asthma); therefore, diagnosis of asthma was not included in the score.

The current authors also used principal component analyses to determine a single continuous score on asthma using optimal weighting for the previous eight questions. However, there was high correlation between this continuous score and a simple sum of the eight questions (Spearman correlation coefficient was 0.99). Therefore, only results for a simple asthma score, calculated as the sum of the eight individual questions, were presented.

The final asthma score used in the analyses consisted of a simple sum of the positive answers to the eight questions, i.e. the score ranged from 0-8 (Appendix 2).

\section{Statistical analyses}

The different operational definitions were compared with the question "Have you ever had asthma" and with BHR (PD20). Sensitivity was the proportion of true asthmatics correctly classified by the test, and specificity the proportion of true nonasthmatics correctly classified by the tests. Positive predictive value (PPV) was the proportion of true asthmatics 
among test positives. In order to be able to compare the different PPV in table 1, a theoretical PPV for a situation, where true prevalence of asthma was $10 \%$, was calculated.

The asthma score was a count, which suggested a Poisson regression model. However, the mean (0.67) was lower than the standard deviation (1.32), which required the use of a negative binomial model. Comparison of the observed distribution of the score with a simulated distribution using this model showed an almost exact match. Therefore, in multivariate analyses, the score was analysed using a negative binomial model, which models the ratio of the mean score among exposed and nonexposed, e.g. a ratio of mean score of 1.63 for maternal asthma meant that those with maternal asthma had a $63 \%$ higher mean score, as compared with those without maternal asthma. The size of this estimate was difficult to compare with results from the logistic regression models used for dichotomous outcomes as they model the relative odds of having the binary outcome. However, z-values were comparable.

\section{RESULTS}

Different definitions gave very different estimates of the prevalence of asthma (table 1). When more positive symptoms were required to define asthma, the sensitivity and prevalence decreased, but specificity increased. Also, requiring a higher asthma score increased the specificity, but decreased the sensitivity of the definition of asthma in a continuous fashion. Although in many very strict definitions the specificity became very high, the PPV remained only moderate, as the sensitivity was so low. The best Youden's index (sensitivity + specificity1) was observed with less strict definitions, especially with wheeze in the last 12 months (data not shown).

When more positive symptoms were required to define asthma, the estimated prevalence differences of the association of atopy with "asthma" were reduced, but the odds ratios (OR) were increased (table 2). However, the statistical significance (measured as z-values) changed very little or was even reduced for definitions with very low prevalences. The highest OR's were achieved defining asthma as a positive answer to all ECRHS definition questions (woken by attack of shortness of breath, attack of asthma and medication for asthma), and the highest levels of score.

Similar results were obtained for maternal asthma, but the increase in OR's were somewhat less pronounced, especially for operational definitions including BHR (data not shown).

TABLE 1

Sensitivity (Sens), specificity (Spec) and positive predictive value (PPV) of different operational definitions of asthma, as compared with "ever asthma" and with bronchial hyperreactivity

\begin{tabular}{|c|c|c|c|c|c|c|c|c|}
\hline & \multirow[t]{2}{*}{$\mathbf{n}$} & \multirow[t]{2}{*}{ Prev \% } & \multicolumn{3}{|c|}{ Ever asthma } & \multicolumn{3}{|c|}{ Bronchial hyperreactivity ${ }^{\#}$} \\
\hline & & & Sens & Spec & PPV & Sens & Spec & PPV \\
\hline \multicolumn{9}{|l|}{ Wheeze } \\
\hline Wheeze & 2443 & 22 & 0.63 & 0.82 & 0.29 & 0.47 & 0.82 & 0.22 \\
\hline Wheeze, breathlessness & 1209 & 11 & 0.48 & 0.92 & 0.45 & 0.31 & 0.93 & 0.29 \\
\hline Slope $>25 \%$ & 2815 & 25 & 0.64 & 0.78 & 0.26 & \multirow{3}{*}{ s } & \multirow{3}{*}{ s } & \multirow{3}{*}{ s } \\
\hline$>20 \%$ at $1 \mathrm{mg}$ & 1538 & 14 & 0.52 & 0.90 & 0.38 & & & \\
\hline Slope $>10 \%$ & 1129 & 10 & 0.42 & 0.93 & 0.42 & & & \\
\hline \multicolumn{9}{|l|}{ Wheeze and BHR ${ }^{\#}$} \\
\hline Wheeze, BHR & 725 & 6.4 & 0.40 & 0.96 & 0.62 & \multirow[b]{2}{*}{$\S$} & \multirow[b]{2}{*}{ \$ } & \multirow[b]{2}{*}{ s } \\
\hline Wheeze, breathlessness, BHR & 481 & 4.3 & 0.32 & 0.98 & 0.75 & & & \\
\hline All 3 variables & 117 & 1.0 & $\S$ & $\S$ & s & 0.06 & 1.00 & 0.59 \\
\hline \multicolumn{9}{|l|}{ Score } \\
\hline Any 1 of 8 questions & 3719 & 32.9 & \multirow{8}{*}{$\S$} & \multirow{8}{*}{$\S$} & \multirow{8}{*}{$\S$} & 0.60 & 0.71 & 0.18 \\
\hline Any 2 of 8 questions & 1679 & 14.9 & & & & 0.40 & 0.89 & 0.27 \\
\hline Any 3 of 8 questions & 937 & 8.3 & & & & 0.28 & 0.95 & 0.34 \\
\hline Any 4 of 8 questions & 538 & 4.8 & & & & 0.20 & 0.98 & 0.98 \\
\hline Any 5 of 8 questions & 344 & 3.0 & & & & 0.15 & 0.99 & 0.50 \\
\hline Any 6 of 8 questions & 212 & 1.9 & & & & 0.11 & 0.99 & 0.56 \\
\hline Any 7 of 8 questions & 115 & 1.0 & & & & 0.06 & 1.00 & 0.59 \\
\hline All 8 questions & 43 & 0.4 & & & & 0.02 & 1.00 & 0.63 \\
\hline
\end{tabular}

Data are presented as n, unless otherwise stated. Prev: prevalence; BHR: bronchial hyperresponsiveness; ECRHS: European Community Respiratory Health Study. ${ }^{\#}$ : >20\% fall in FEV1 at $1 \mathrm{mg}$; ": theoretical PPV, if true prevalence of asthma $10 \%{ }^{+}{ }^{*}$ : woken by shortness of breath, attack of asthma or asthma medication; ${ }^{\S}$ : part of the definition. 
This was not unexpected as bronchial responsiveness has an association with atopy independent of asthma [19].

There was no evidence of a threshold in the association of asthma score with demographic factors, indicators of severity of asthma and risk factors of asthma (table 3). Most indicators of severity and risk factors increased continuously with increasing score, including BHR (fig. 1). For variables measuring tobacco smoke exposure, especially active smoking, there was first an increase in prevalence, then a decline, suggesting a more complex association with the score.

In a multivariate model assessing a combination of risk factors (table 4), the largest $\mathrm{z}$-values were obtained for the risk factors when analysing the continuous asthma score (using negative binomial model), as compared with logistic regression of the usual dichotomous definitions. This suggests an increase in the power of the analyses with the use of the score.

To analyse more directly the additional information provided by the asthma score, multivariate logistic regression models were also run with BHR as a dependent variable, and the three definitions of asthma in table 4, age, sex, and centre as independent variables. The adjusted OR (z-value) for asthma score was 1.50 (10.9). The same models for atopy and for maternal asthma gave adjusted OR's (z-values) for asthma score of 1.25 (7.3) and 1.30 (5.2), respectively. These analyses show that, even when adjusting for the other two definitions of asthma, the asthma score provides additional information on all of the three variables (BHR, atopy and maternal asthma) used.

In an attempt to analyse risk factors of different phenotypes of asthma (table 5), the current authors undertook further analyses retaining all the three main factors identified in the initial principal component analysis. After varimax rotation, good separation of the factors was obtained. The first factor, "asthma", had loadings between 0.76 and 0.91 with the four questions on asthma (question 13 and its subquestions), but loadings $<0.26$ with other questions. The second factor, "wheeze", had loadings between 0.73 and 0.90 with the three questions on wheeze (question 1 and its subquestions), but loadings $<0.36$ with other questions. The third factor, "shortness of breath", had loadings between 0.60 and 0.74 with questions 2,3 , and 5, a loading of $\sim 0.35$ with questions 4 and 6 , and loadings $<0.26$ with other questions.

For analyses on risk factors, the scores were dichotomomised at $\sim 90$ th percentile. Due to discontinuities in the distributions of the scores, this resulted in a prevalence of $7.6 \%$ for the asthma factor (all subjects with ever asthma), a prevalence of $8.6 \%$ for wheeze and a prevalence of $10.0 \%$ for the dichotomised shortness of breath factor.

TABLE 2 Association of atopy with different operational definitions of asthma

\begin{tabular}{|c|c|c|c|c|c|c|}
\hline Operational definition of asthma & Nonatopic \% & Atopic \% & Adj OR $\#$ & Lower $95 \% \mathrm{Cl}$ & Upper $95 \%$ Cl & z-value \\
\hline Subjects $n$ & 7457 & 3840 & & & & \\
\hline Wheeze & 17.9 & 28.9 & 1.84 & 1.67 & 2.02 & 12.62 \\
\hline Wheeze, breathlessness & 8.1 & 15.8 & 2.12 & 1.88 & 2.40 & 11.87 \\
\hline Wheeze, breathlessness, no cold & 4.7 & 11.8 & 2.61 & 2.25 & 3.03 & 12.61 \\
\hline$>20 \%$ at $1 \mathrm{mg}$ & 8.9 & 22.7 & 3.20 & 2.85 & 3.59 & 19.74 \\
\hline Slope $>10 \%$ & 6.1 & 17.5 & 3.46 & 3.03 & 3.95 & 18.38 \\
\hline \multicolumn{7}{|l|}{ Wheeze and BHR } \\
\hline Wheeze, BHR & 3.4 & 12.4 & 4.13 & 3.50 & 4.86 & 16.94 \\
\hline Wheeze, breathlessness, BHR & 1.9 & 8.8 & 4.98 & 4.05 & 6.11 & 15.29 \\
\hline All 3 variables & 0.3 & 4.7 & 6.92 & 4.42 & 10.84 & 8.47 \\
\hline \multicolumn{7}{|l|}{ Score } \\
\hline Any 1 of 8 questions & 29.0 & 40.4 & 1.70 & 1.56 & 1.85 & 12.16 \\
\hline Any 2 of 8 questions & 11.6 & 21.3 & 2.12 & 1.90 & 2.36 & 13.50 \\
\hline Any 3 of 8 questions & 5.7 & 13.3 & 2.57 & 2.23 & 2.95 & 13.20 \\
\hline Any 4 of 8 questions & 2.7 & 8.8 & 3.41 & 2.84 & 4.11 & 13.00 \\
\hline Any 5 of 8 questions & 1.5 & 6.1 & 4.39 & 3.46 & 5.56 & 12.19 \\
\hline Any 6 of 8 questions & 0.7 & 4.1 & 5.77 & 4.18 & 7.95 & 10.69 \\
\hline Any 7 of 8 questions & 0.4 & 2.3 & 6.55 & 4.20 & 10.21 & 8.30 \\
\hline All 8 questions & 0.1 & 0.9 & 7.01 & 3.33 & 14.78 & 5.12 \\
\hline
\end{tabular}

Adj: adjusted; OR: odds ratio; Cl: confidence interval; BHR: bronchial hyperresponsivness; ECRHS: European Community Respiratory Health Study. \#: adjusted for age sex and centre; ${ }^{\bullet}:>20 \%$ fall in forced expiratory volume in one second at $1 \mathrm{mg} ;{ }^{+}$: woken by shortness of breath, attack of asthma or asthma medication. 


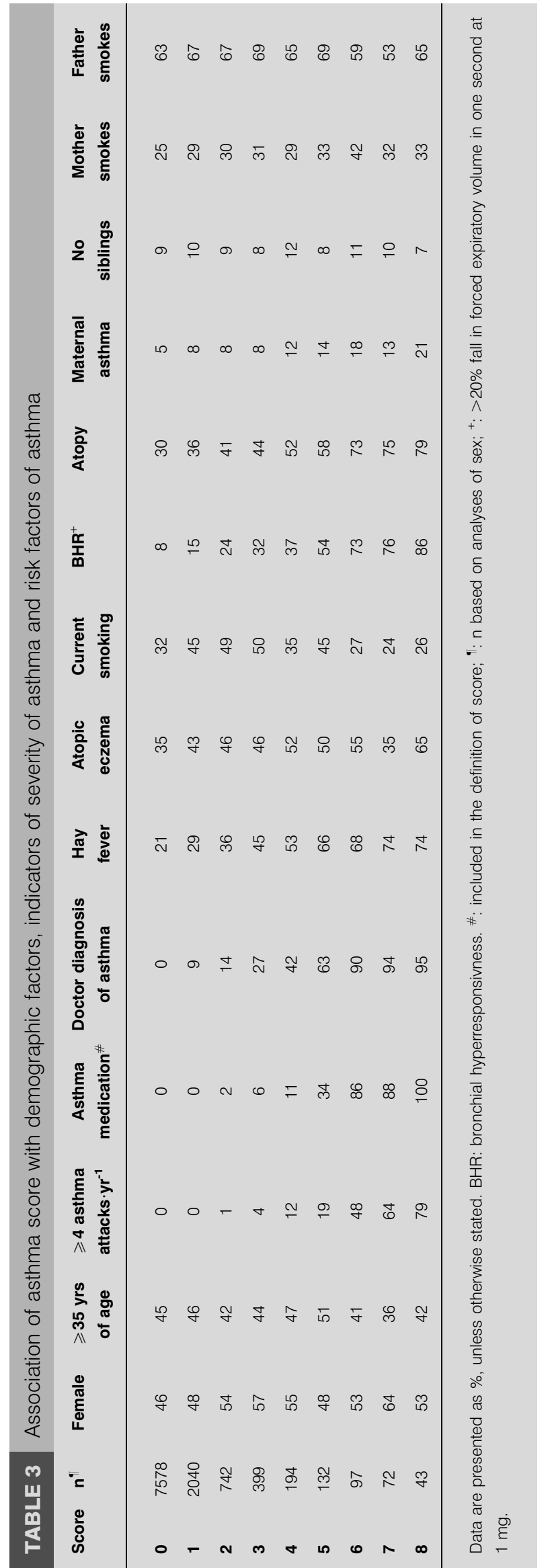

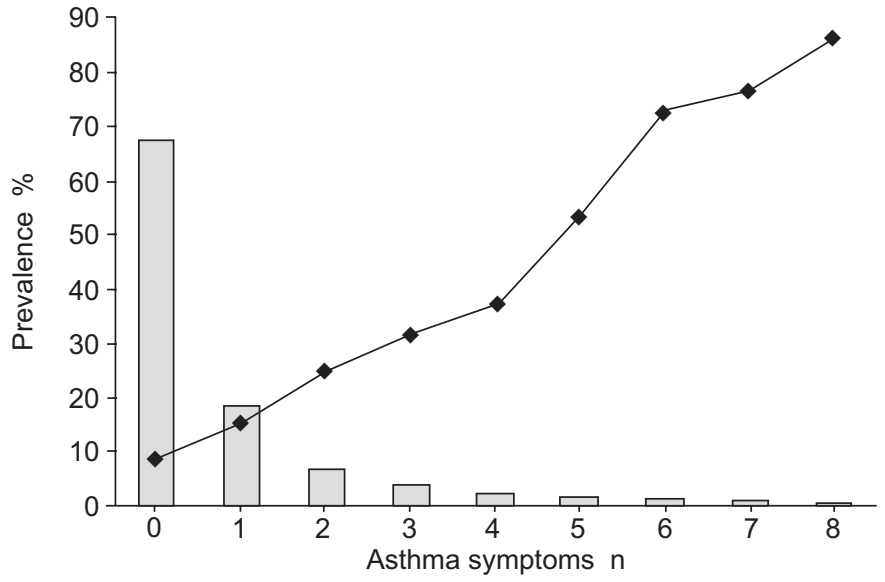

FIGURE 1. Prevalence (\%) of subjects with a given number of asthma symptoms ( $\square$ ) and the association with prevalence (\%) of bronchial hyperresponsiveness (PD20; $\longrightarrow$ ).

Maternal asthma, atopy and BHR were most strongly associated with the asthma factor, but there was also clear association with the other two factors (table 5). Smoking was associated mainly with the wheeze factor, whereas older age and female sex were mostly associated with the shortness of breath factor.

\section{DISCUSSION}

The most common operational definitions of asthma in epidemiological studies today are based on the questionnaires and definitions of asthma developed for international prevalence studies, such as the ECRHS [3] in adults and ISAAC [4] among children. The ECRHS defines asthma usually as the presence of either an attack of shortness of breath, an attack of asthma or use of asthma medication [15]. ISAAC focuses on the presence of wheezing [4]. However, definitions of asthma used in these studies may not be optimal for future studies on risk factors of asthma for two reasons. First, the definitions are dichotomous and secondly, the definitions have been developed with more focus on prevalence of asthma rather than on risk factors of asthma [20].

Whether asthma is a truly dichotomous disease is unknown. Current knowledge on the pathophysiology and natural history of asthma does not strongly suggest that asthma would be different from most other chronic diseases that exist as a continuum in the population [7]. This is especially clear when asthma is measured using symptom questionnaires, as the reporting of symptoms is also influenced by many other factors, such as perception of symptoms and current environmental exposures. The present analyses showed no threshold in the association between increasing number of asthma symptoms and any of the markers of asthma severity, or main risk factors of asthma, which would have suggested a dichotomous definition of asthma. Using a continuous asthma score instead of a dichotomous definition of asthma is likely to increase the power of the study [6], which is especially important in smaller population based studies. This was observed in the current analyses. Taken together this suggests that when analysing symptoms of asthma in epidemiological 
TABLE 4 Multivariate ${ }^{\#}$ associations of selected factors with different operational definitions of asthma

\begin{tabular}{|c|c|c|c|c|c|c|c|c|c|c|c|c|}
\hline & \multicolumn{4}{|c|}{ Wheeze, breathlessness (binary) } & \multicolumn{4}{|c|}{ ECRHS definition" (binary) } & \multicolumn{4}{|c|}{ Score (continuous) } \\
\hline & OR & $\begin{array}{l}\text { Lower } \\
95 \% \mathrm{Cl}\end{array}$ & $\begin{array}{l}\text { Upper } \\
95 \% \mathrm{Cl}\end{array}$ & z-value & OR & $\begin{array}{l}\text { Lower } \\
95 \% \mathrm{Cl}\end{array}$ & $\begin{array}{l}\text { Upper } \\
95 \% \mathrm{Cl}\end{array}$ & z-value & $\begin{array}{l}\text { Relative } \\
\text { change }^{+}\end{array}$ & $\begin{array}{l}\text { Lower } \\
95 \% \mathrm{Cl}\end{array}$ & $\begin{array}{l}\text { Upper } \\
95 \% \mathrm{Cl}\end{array}$ & z-value \\
\hline Maternal asthma & 1.81 & 1.45 & 2.26 & 5.25 & 1.85 & 1.44 & 2.38 & 4.83 & 1.63 & 1.44 & 1.86 & 7.52 \\
\hline Atopy & 1.69 & 1.48 & 1.93 & 7.77 & 2.02 & 1.73 & 2.36 & 8.87 & 1.48 & 1.38 & 1.59 & 10.55 \\
\hline Ex-smoking & 1.14 & 0.95 & 1.37 & 1.46 & 1.17 & 0.96 & 1.42 & 1.55 & 1.15 & 1.05 & 1.26 & 2.91 \\
\hline Age $30-39$ yrs & 0.91 & 0.79 & 1.05 & -1.32 & 0.97 & 0.82 & 1.15 & -0.38 & 0.94 & 0.87 & 1.01 & -1.68 \\
\hline Age $>40$ yrs & 0.97 & 0.81 & 1.16 & -0.30 & 1.22 & 1.00 & 1.50 & 1.94 & 1.04 & 0.94 & 1.14 & 0.74 \\
\hline Female & 1.10 & 0.97 & 1.25 & 1.42 & 1.04 & 0.89 & 1.20 & 0.45 & 1.20 & 1.12 & 1.29 & 5.23 \\
\hline
\end{tabular}

ECRHS: European Community Respiratory Health Study; OR: odds ratio; Cl: confidence intervals; BHR: bronchial hyperresponsivness. \#: OR calculated using logistic regression and relative change in mean score using negative binomial model, adjusting for centre and all the other variables in the table; ${ }^{\circ}$ : any one of the three variables (woken by shortness of breath, attack of asthma, or asthma medication); ${ }^{+}$: for interpretation of the relative change, see statistical methods; ${ }^{\S}$ : $20 \%$ fall in forced expiratory volume in one second at $1 \mathrm{mg}$.

studies, they are best analysed as a continuum, not as a dichotomy.

If it is accepted that asthma symptoms exist as a continuum in the population, choosing the cut-off point to classify subjects into asthmatics and nonasthmatics is a somewhat arbitrary decision, which depends mainly on the aims of the classification, e.g. when screening for a disease, the definition needs to be very sensitive. International studies comparing prevalence of asthma have focused on questions on asthma symptoms, such as wheeze, which have a high combination of specificity and sensitivity [3]. In aetiological research and in clinical practise, there is more emphasis on specificity and PPV [20, 21].

The present study indicates that requiring positive answers to several questions on symptoms of asthma increases the specificity and PPV, but reduces sensitivity of the definition, when compared against self-report of ever asthma or BHR. The estimated sensitivities and specificities should, however, be interpreted more as measures of agreement than as a true validation study, given the lack of a true gold standard for asthma [2]. However, as expected based on theory, the observed OR increased with increasing PPV of the definition [21]. PPV is a function of true prevalence of the disease, specificity, and sensitivity [22-24]. In general, when the specificity is $<95 \%$, there is substantial bias in the estimated risk ratios.

In the main analyses of the present study, a single asthma score was used. This was done as asthma is usually treated as a single disease in epidemiological studies. Previous analyses [13] also suggest that the asthma symptom questions in the ECRHS mostly measure one single underlying factor or latent trait. This was supported by the present principal component

TABLE 5 Multivariate\# ${ }^{\#}$ associations of selected factors with different phenotypes" of asthma

\begin{tabular}{|c|c|c|c|c|c|c|c|c|c|c|c|c|}
\hline & \multicolumn{4}{|c|}{ Asthma factor } & \multicolumn{4}{|c|}{ Wheeze factor } & \multicolumn{4}{|c|}{ Shortness of breath factor } \\
\hline & OR & $\begin{array}{l}\text { Lower } \\
95 \% \mathrm{Cl}\end{array}$ & $\begin{array}{l}\text { Upper } \\
95 \% \mathrm{Cl}\end{array}$ & z-value & OR & $\begin{array}{l}\text { Lower } \\
95 \% \mathrm{Cl}\end{array}$ & $\begin{array}{l}\text { Upper } \\
95 \% \mathrm{Cl}\end{array}$ & z-value & OR & $\begin{array}{l}\text { Lower } \\
95 \% \mathrm{Cl}\end{array}$ & $\begin{array}{l}\text { Upper } \\
95 \% \mathrm{Cl}\end{array}$ & z-value \\
\hline Maternal asthma & 2.27 & 0.95 & 2.95 & 6.19 & 1.60 & 1.25 & 2.05 & 3.71 & 1.52 & 1.20 & 1.92 & 3.46 \\
\hline Atopy & 3.29 & 2.78 & 3.91 & 13.64 & 1.43 & 1.22 & 1.66 & 4.61 & 1.29 & 1.22 & 1.49 & 3.57 \\
\hline Ex-smoking & 0.98 & 0.79 & 1.22 & -0.19 & 1.24 & 1.00 & 1.56 & 1.92 & 1.31 & 0.99 & 1.42 & 1.86 \\
\hline Age $30-39$ yrs & 0.79 & 0.66 & 0.95 & -2.46 & 0.84 & 0.72 & 0.99 & -2.06 & 0.96 & 0.82 & 1.12 & -0.54 \\
\hline Age $>40$ yrs & 0.85 & 0.68 & 1.07 & -1.41 & 0.85 & 0.69 & 1.04 & -1.58 & 1.17 & 0.97 & 1.40 & 1.66 \\
\hline Female & 1.07 & 0.91 & 1.26 & 0.77 & 1.11 & 0.96 & 1.28 & 1.43 & 1.38 & 1.21 & 1.58 & 4.69 \\
\hline
\end{tabular}

OR: odds ratio; Cl: confidence interval; BHR: bronchial hyperresponsivness. \#: OR calculated using logistic regression, adjusting for centre and all the other variables in the table. ": phenotypes based on dichotomised scores from principal component analysis of the 12 questions on asthma symptoms. The first factor corresponds closely to the question on ever asthma, second factor to questions on wheeze, and third factor on questions on chest tightness and shortness of breath. 
analyses. The current authors used only the simple sum of the eight asthma questions, due to simplicity and the high correlation $(r=0.99)$ between the simple sum and a continuous score that can be calculated based on the principal component analysis.

However, it is possible that asthma is a more heterogeneous disease entity with several different phenotypes. Earlier analyses of the ECRHS questionnaire [25] separated two different phenotypes of asthma, namely "asthma" and "wheeze". The present analyses on phenotypes confirmed the earlier findings on the risk factors of these two phenotypes. The present analyses included, in addition, a third phenotype, "shortness of breath", which was most strongly associated with female sex and older age.

The possibility to separate different phenotypes of asthma and to create continuous scores of these phenotypes using only the current questions is, however, limited. Two-thirds of the subjects had no positive replies to the questions on asthma symptoms. Future analyses should try to obtain information on longer symptom histories (not just the past 12 months), use symptom questions, which are not dichotomised, but have continuous scales, and also include information on possible objective markers of asthma.

When the asthma score is used in epidemiological analyses, it is important to explore if the risk factor under study increases in a continuous manner with increasing level of the score. In the present study this was observed for all risk factors of asthma except smoking. As observed before [25], smoking was also more strongly associated with questions on wheezing than with questions on asthma. Therefore, it is probably advisable to stratify future analyses by smoking, at least as a sensitivity analyses. For example, in the present analyses, the association between asthma score and BHR was slightly weaker among smokers than among nonsmokers. However, the difference in the OR was small (1.37 versus 1.52$)$.

In conclusion, the present study suggests that there is no threshold in the association between increasing number of asthma symptoms and any of the markers of asthma severity or main risk factors of asthma. Using definitions that require positive answers to several asthma symptom questions strengthened the associations with the studied risk factors and also increased the estimated specificity and positive predictive value of the definition. However, statistical power differed very little. In contrast, using a continuous asthma score both improved the power of the analyses and gave additional information to the dichotomous definitions of disease. This suggests that symptoms of asthma are possibly best analysed as a continuous asthma score in epidemiological studies.

\section{ACKNOWLEDGEMENTS}

The principal participants of the European Community Respiratory Health Study (ECRHS) are as follows. Australia: M. Abramson, J. Kutin (Melbourne); Belgium: P. Vermeire, F. van Bastelaer (Antwerp South, Antwerp Central); France: J. Bousquet (Montpellier), F. Neukirch, R. Liard (Paris), I. Pin, C. Pison (Grenoble), A. Taytard (Bordeaux); Germany: H. Magnussen, D. Nowak (Hamburg), H.E. Wichmann,
J. Heinrich (Erfurt); Iceland: T. Gislason, D. Gislason (Reykjavik); Ireland: J. Prichard, S. Allwright, D. MacLeod (Dublin); Italy: M. Bugiani, C. Bucca, C. Romano (Turin), R. de Marco, V. Lo Cascio, C. Campello (Verona), A. Marinoni, I. Cerveri, L. Casali (Pavia); The Netherlands: B. Rijcken, A. Kremer (Groningen, Bergen-op-Zoom, Geleen); New Zealand: J. Crane, S. Lewis (Wellington, Christchurch, Hawkes Bay); Norway: A. Gulsvik, E. Omenaas (Bergen); Spain: J. Antó, J. Sunyer, J. Soriano, A. Tobías, J. Roca, M. Kogevinas (Barcelona), N. Muniozguren, J. Ramos González, A. Capelastegui (Galdakao), J. Martinez-Moratalla, E. Almar (Albacete), J. Maldonado, A. Pereira, J. Sánchez (Huelva), F. Payo, I. Huerta (Oviedo); Sweden: G. Boman, C. Janson, E. Bjornsson (Uppsala), L. Rosenhall, E. Norrman, B. Lundback (Umea), N. Lindholm, P. Plaschke (Goteborg); Switzerland: U. Ackermann-Liebrich, N. Künzli, A. Perruchoud (Basel); United Kingdom: M. Burr, J. Layzqll (Caerphilly), R. Hall (Ipswich), B. Harrison, (Norwich), J. Stark (Cambridge); Coordinating Centres, London, UK: P. Burney, S. Chinn, C. Luczynska, D. Jarvis, E. Lai; USA: S. Buist, W. Vollmer, M. Osborne (Portland, $\mathrm{OH}$ ).

The following grants helped to fund the local studies. Australia: Allen and Hanbury's; Belgium: Belgian Science Policy Office, National Fund for Scientific Research; France: Ministère de la Santé, Glaxo France, Institut Pneumologique d'Aquitaine, Contrat de Plan Etat-Région LanguedocRousillon, CNMATS, CNMRT (90MR/10, 91AF/6), Ministre delegué de la santé, RNSP; Germany: GSF and the Bundesminister für Forschung und Technologie, Bonn; Greece: The Greek Secretary General of Research and Technology, Fisons, Astra, Boehringer-Ingelheim; India: Bombay Hospital Trust; Italy: Ministero dell'Università e della Ricerca Scientifica e Tecnologica, CNR, Regione Veneto grant RSF n. 381/05.93; New Zealand: Asthma Foundation of New Zealand, Lotteries Grant Board, Health Research Council of New Zealand; Norway: Norwegian Research Council project no. 101422/310; Portugal: Glaxo Farmacêutica Lda, Sandoz Portugesa; Spain: Ministero Sanidad y Consumo FIS grants \#91/0016060/00E-05E and \#93/0393, Red Respira RTIC 03/ 11, ISC III, and grants from Hospital General de Albacete, Hospital General Juan Ramón Jiménenz, Consejeria de Sanidad Principado de Asturias; Sweden: The Swedish Medical Research Council, the Swedish Heart Lung Foundation, the Swedish Association against Asthma and Allergy; Switzerland: Swiss national Science Foundation grant 4026-28099 and PROSPER 32-48922.96 (NK); United Kingdom: National Asthma Campaign, British Lung Foundation, Department of Health, South Thames Regional Health Authority; USA: United States Department of Health, Education and Welfare Public Health Service grant no. 2 S07 RR05521-28.

\section{APPENDIX 1 \\ Questions used to devise different operational definitions of asthma}

1. Wheezing or whistling in your chest in the last 12 months 1.1 If yes to 1 , breathless when wheezing sound present 1.2 If yes to 1 , wheezing and whistling without cold

2. Woken up with a feeling of chest tightness in the last 12 months

3. Attack of shortness of breath at rest in the last 12 months 
4. Attack of shortness of breath after exercise in the last 12 months

5. Woken by attack of shortness of breath in the last 12 months

6. Woken by attack of coughing in the last 12 months

13. Have you ever had asthma

13.1 If yes to 13 , diagnosis by a doctor

13.5 If yes to 13 , attacks of asthma in the last 12 months

13.6 If yes to 13, medication for asthma

\section{APPENDIX 2}

\section{Questions from Appendix 1 used to produce a continuous asthma score}

1. Wheeze and breathless (yes to questions 1 and 1.1)

2. Feeling of chest tightness (question 2)

3. Attack of shortness of breath at rest (question 3)

4. Attack of shortness of breath after exercise (question 4)

5. Woken by attack of shortness of breath (question 5)

6. Ever asthma (question 13)

7. Attack of asthma (question 13.5)

8. Medication for asthma (question 13.6)

\section{REFERENCES}

1 Pearce N, Beasley R, Burgess C, et al., Asthma epidemiology: principles and methods. New York, Oxford University Press, 1998.

2 Gross NJ. What is this thing called love?-or, defining asthma. Am Rev Respir Dis 1980; 121: 203-204.

3 Burney PGJ, Laitinen L-A, Perdrizet S, et al. Validity and repeatability of the IUALTD (1984) bronchial symptoms questionnaire: an international comparison. Eur Respir J 1989; 2: 940-945.

4 Worldwide variation in prevalence of symptoms of asthma, allergic rhinoconjunctivitis, and atopic eczema: ISAAC. The International Study of Asthma and Allergies in Childhood (ISAAC) Steering Committee. Lancet 1998; 351: 1225-1232.

5 Lewis SA, Weiss ST, Britton JR. Airway responsiveness and peak flow variability in the diagnosis of asthma for epidemiological studies. Eur Respir J 2001; 18: 921-927.

6 MacCallum RC, Zhang S, Preacher KJ, Rucker DD. On the practise of dichotomization of quantitative variables. Psychol Methods 2002; 7: 19-40.

7 Rose G. The Strategy of preventive medicine. London, Oxford University Press, 1993.

8 Pickering GW. High blood pressure. New York, Raven Press, 1955.

9 Brayne C, Calloway P. Normal ageing, impaired cognitive function, and senile dementia of the Alzheimer's type: A continuum? Lancet 1988; 4: 1265-1267.

10 McDowell I, Newell C. Measuring health. A quide to rating scales and questionnaires. New York, Oxford University Press, 1996.
11 Curtis JR, Martin DP, Martin TR. Patient-assessed health outcomes in chronic lung disease. Am J Respir Crit Care Med 1997; 156: 1032-1039.

12 Shaw RA, Crane J, Pearce NE, et al. Comparison of a video questionnaire with the IUATLD written questionnaire for measuring asthma prevalence. Clin Exp Allergy 1992; 22: 561-568.

13 Biino G, Rezzani C, Grassi M, et al. ECRHS screening questionnaire scoring: a methodological suggestion for asthma assessment. J Outcome Res 2000-2001; 4: 740-762.

14 Burney PGJ, Luczynska P, Chinn S, et al. The European Community Respiratory Health Survey. Eur Respir J 1994; 7: 954-960.

15 Janson C, Anto J, Burney P, et al. The European Community Respiratory Health Survey: what are the main results so far? European Community Respiratory Health Survey II. Eur Respir J 2001; 18: 598-611.

16 Burney PGJ, Chinn S. Developing a new questionnaire for measuring the prevalence and distribution of asthma. Chest 1987; 91: Suppl. 6, 79S-83S.

17 European Community Respiratory Health Survey. Variations in the prevalence of respiratory symptoms, self-reported asthma attacks, and use of asthma medication in the European Community Respiratory Health Survey. Eur Respir J 1996; 9: 687-695.

18 Chinn S, Burney P, Jarvis D, et al. on behalf of the European Community Respiratory Health Survey. Variation in bronchial responsiveness in the European Community Respiratory Health Survey (ECRHS). Eur Respir J 1999; 10: 2495-2501.

19 Postma DS, Bleecker ER, Amelung PJ, et al. Genetic susceptibility to asthma-bronchial hyperresponsiveness coinherited with a major gene for atopy. $N$ Engl J Med 1995; 333: 894-900.

20 Pekkanen J, Pearce N. Defining asthma in epidemiological studies. Eur Respir J 1999; 14: 951-957.

21 Brenner $\mathrm{H}$, Gefeller O. Use of positive predictive value to correct for disease misclassification in epidemiological studies. Am J Epidemiol 1993; 138: 1007-1015.

22 Copeland KT, Checkoway H, McMichael AJ, et al. Bias due to misclassification in the estimation of relative risk. Am J Epidemiol 1977; 105: 488-495.

23 Green MS. Use of predictive value to adjust relative risk estimates biased by misclassification of outcome status. Am J Epidemiol 1983; 117: 98-105.

24 Poole C. Exception to the rule about nondifferential misclassification. Am J Epidemiol 1985; 122: 508.

25 Sunyer J, Basagana $X$, Burney $P$, et al. International assessment of the internal consistency of respiratory symptoms. European Community Respiratory Health Study (ECRHS). Am J Respir Crit Care Med 2000; 162: 930-935. 